\title{
El espacio rural entre la producción y el consumo: algunas referencias para el caso argentino
}

\author{
Marcelo Posada*
}

\begin{abstract}
In this short article we want to reflect about the modifications that have been occurred in the rural means as well as in the conceptualizations that have been elaborated at this respect. In the developed countries, and in the South' countries too, the rural area at the end of the century is different in so many aspects that we could observe some decades ago. It is not only about changes in the functional or physical aspects, but also we face some deep mutations in the way of valuing to the rural by the urban, this implicate that is modeled (structural and functionality) in base to these valuations.

An of the most complete expressions of these modifications are the changes in the conceptualization of the use of rural's space: before this changes it was a space for the production, nowadays it is a space for the consumption. But not for the consumption of the produced, but for the consumption of the space in itself. The rural tourism, in their multiple facets is a clear example of this.
\end{abstract}

Key words: rurality, rural tourism, Argentina.

\section{Resumen}

En este breve artículo nos proponemos reflexionar en torno a las modificaciones que han ocurrido tanto en el medio rural como en las conceptualizaciones que se elaboraron respecto a éste. En los países desarrollados, pero también en los del Sur, el ámbito rural de fines de siglo se diferencia en mucho al que podíamos observar hace apenas unas décadas. No se trata sólo de cambios en los aspectos físicos o funcionales, sino que también enfrentamos unas mutaciones profundas en la manera de valorar a lo rural por parte de lo urbano, lo que conlleva a que aquél se modele (estructural y funcionalmente) en base a estas valoraciones.

Una de las expresiones más acabadas de estas modificaciones son los cambios en la conceptualización del uso de lo rural: antes era un espacio para la producción, hoy es un espacio para el consumo. Pero no para el consumo de lo producido, sino para el consumo del espacio en sí. El turismo rural, en sus múltiples facetas, es un claro ejemplo de esto.

Palabras claves: ruralidad, turismo rural, Argentina.

* Conicet / FLACSO Argentina

Investigador Principal del Area de Estudios Agrarios de la FLAcso Argentina

Profesor Adjunto de la Universidad Nacional de Luján, Argentina

Dirección postal: Díaz Colodrero $253710^{\circ} \mathrm{C}$

(1431) Capital Federal Argentina. Tel./fax: 54-11-4521 1055. E-mail: posada@mail.retina.ar

Revista eure (Vol. XXV, N 75), pp. 63-76, Santiago de Chile, septiembre 1999 


\section{INTRODUCCIÓN}

$\mathrm{E}$ n este artículo nos proponemos reflexionar en torno a las modificaciones que han ocurrido tanto en el medio rural como en las conceptualizaciones que se elaboraron respecto a éste. En los países desarrollados, pero también en los del Sur, el ámbito rural de fines de siglo se diferencia en mucho al que podíamos observar hace apenas unas décadas. No se trata de cambios en los aspectos físicos o funcionales, sino que también enfrentamos unas mutaciones profundas en la manera de valorar a lo rural por parte de lo urbano, lo que conlleva a que aquél se modele (estructural y funcionalmente) en base a estas valoraciones.

Una de las expresiones más acabadas de estas modificaciones son los cambios en la conceptualización del uso de lo rural: antes era un espacio para la producción, hoy es un espacio para el consumo. Pero no para el consumo de lo producido, sino para el consumo del espacio en sí. El turismo rural, en sus múltiples facetas, es un claro ejemplo de esto.

En las páginas siguientes abordaremos estas cuestiones en sólo dos apartados, estructurados a manera de una reflexión general acerca de la ruralidad contemporánea, el primero, y como un panorama de la actividad turística rural, el segundo. Si bien en ambas secciones apuntamos a analizar el medio rural y sus concepciones desde una perspectiva amplia, en razón de nuestras preocupaciones intelectuales, optamos por relacionar varias de las reflexiones con la realidad argentina, lo que, esperamos, no interfiera en la comprensión general del texto.

\section{Cambios Reales Y mutaciones CONCEPTUALES ALREDEDOR \\ DE LO RURAL}

El medio rural se ha convertido a lo largo de los últimos quince o veinte años en un tópico de reflexión. A veces impulsada por una preocupación conservacionista (con diferentes matices, desde el ecologismo radicalizado hasta el nacionalismo más ultramontano), otras veces montada sobre un proceso revalorativo (el rescate por los urbanitas de los valores que perciben -o creen hacerloen el campo y sus habitantes).

Este centro de la escena que ocupa el medio rural se observa en espacios institucionalizados pero también en otros ámbitos "alternativos". La reforma de la Política Agraria Comunitaria de la hoy Unión Europea, que gira de un tinte netamente productivista hacia otro en el que priva un enfoque holístico del medio que sustenta la producción agropecuaria, con especial preocupación por el futuro de ese espacio, y la implementación de un plan integral de desarrollo rural a nivel de dicha Unión (sintetizado en el documento El futuro del mundo rural europeo), ${ }^{1}$ son dos claros ejemplos de la importancia institucional del asunto que nos ocupa. Por su parte, su centralidad "alternativa" puede observarse en la configuración de ciertos movimientos cuasi-neorrománticos que pululan en distintos países europeos y en los Estados Unidos, postulando "una vuelta al campo". ${ }^{2}$

El ámbito rural deja de ser considerado unánimemente como el espacio que sustenta la producción de alimentos, tal como se lo veía hasta no hace mucho

\footnotetext{
1 Cfr. C.C.E. (1992).

2 Cfr. J. Nogué i Font (1988).
} 
El espacio rural entre la producción y el consumo

tiempo. Hoy se lo concibe (y percibe) como un ámbito de múltiples actividades, entre las cuales la producción alimenticia en su primera fase es sólo una más, quizás aún la más importante, pero no ya la única. De hecho, esta circunstancia alcanzó tal magnitud que se ha constituido una nueva noción sociológica en el abordaje de los procesos sociales agrarios: la agricultura a tiempo parcial (ATP). La pluriactividad conlleva, las más de las veces, al pluriempleo, y esto no puede desconocerse al momento del análisis de la acción social de los actores. Y aún más, no debe dejarse de lado esto cuando se realiza el enfoque desde lo espacial: si el espacio es construido por el hombre, la nueva dinámica que éste desenvuelve al ejercer distintas actividades simultáneamente trastoca la organización espacial que se indague.

La magnitud de este cambio de concepción y de percepción del medio rural se ejemplifica bien si se compara el tiempo transcurrido para su consolidación, las dos décadas mencionadas al principio, contra la larga tradición que cimentó la concepción del campo como proveedor de alimentos a la ciudad. Esta noción encontraba a un ámbito agrario aislado, ensimismado, tradicionalista, que sólo se contactaba con el "exterior" (la ciudad) para vender su producción de alimentos. Unicamente las áreas rurales más próximas a los centros urbanos tenían contactos más asiduos con éstos, no sólo para venderles lo producido allí.

Sobre esta idea de medio rural aislado y agrícola pivotean una buena cantidad de análisis, entre ellos varios desarrollos conceptuales que fueron (y en algunos casos aún lo son) claves para el progreso del conocimiento rural desde las ciencias sociales. Tönnies, Durkheim, Sorokin-Zimmerman, con diferencias entre sí, son algunos de los clásicos auto- res que asentaron las bases de esta tradición en el enfoque del medio rural.

A medida que la ciudad crecía física, demográfica y económicamente, su influencia cultural se acrecentaba también. $\mathrm{Su}$ reclamo sobre el campo (alimentos y mano de obra) aumentaba paralelamente a aquel crecimiento. De tal manera, el mundo rural veía disminuir su autonomía decisional, sentía el enflaquecimiento de su espesura societal y, en definitiva, observaba cómo era cooptado por la ciudad. Lentamente, los valores ciudadanos (coincidentes, claro está, con los capitalistas) se sobreponen a buena parte de los valores rurales. Un ejemplo: la noción de "comunidad", con sus colaterales de conocimiento interpersonal y de arraigo en el lugar, deja espacio a la valorización de la "sociedad" (o "asociación”, en términos de Tönnies), en la cual el conocimiento se despersonaliza y se pierde la sujeción atávica al terruño.

El proceso de urbanización, entonces, significaba la desruralización de la sociedad. Ahora habria habitantes que por diferentes motivos se asientan en espacios "poco densos", que se dedican a la producción agropecuaria, pero que, en esencia, no se diferencian en gran medida de los urbanitas. El espectacular avance en la expansión de los medios de difusión/comunicación terminó por romper el precepto del aislamiento rural: ¿cuán aislado está un habitante rural que por las noches se transforma en un cibernauta de Internet?, ¿cuánto lo está aquel que conoce al momento los hechos políticos, sociales o deportivos a través de la TV por cable que baja la señal de la CNN?

$\mathrm{Si}$, como decíamos, el aislamiento parece superado, qué pasa con el otro pilar de lo rural: su papel de espacio productor de alimentos o materias primas agropecuarias. 
Marcelo Posada

Este es, quizás, el pilar más fuerte de la tradicional concepción respecto al medio rural. Aún en su versión más modernizada, se considera al campo sólo como productor ("industrializado", si se quiere) de alimentos o de materia prima para éstos. A su vez, como esa demanda urbana de alimentos crecía más deprisa que el ritmo de producción, se impulsaron una serie de cambios técnicos que posibilitaron un incremento notable en la productividad agrícola (la mecanización fue el primero, pero las tecnologías químicas y biológicas fueron las que dieron el impulso necesario para producir acorde a la demanda y, en muchos casos, superarla). El resultado de esto fue un elevado volumen de producción obtenido gracias a la productividad de los recursos implicados: suelo y capital. El tercero en discordia, el trabajo, fue el que debió ser sacrificado para alcanzar esos resultados. Sin embargo, esto no fue visto como un gran problema, porque coincidía con la demanda urbanoindustrial de mano de obra: el trabajo redundante en un lado era trabajo demandado en otro. El equilibrio parecía saldado, y no se cuentan muchos documentos contemporáneos que acrediten preocupación por ese problema de la emigración del campo a la ciudad. ¿Quién planteaba como problema en los años '40 o '50 que los pobladores rurales argentinos abandonen el campo y se instalen en el litoral desde Rosario hasta La Plata? ¿Quién señaló como peligroso que los campesinos españoles, italianos, franceses o alemanes abandonen sus terruños, ahora mecanizados, y se ocupen en actividades urbanas en plena Europa de la reconstrucción? La respuesta es la misma para ambas cuestiones: casi nadie. ${ }^{3}$

\footnotetext{
3 Se nos podrá indicar que en Argentina sí se pueden contabilizar algunos autores que se expresaron preocupados por esa emigración, tal el caso de Celestino Sienrra (1946), pero ni su número ni el impacto de sus dis-
}

Después sí, cuando la capacidad de absorción urbano-industrial se saturó, cuando la dinámica expansiva de la industria alcanzó un techo de productividad en base al patrón tecnológico vigente o cuando entró en crisis (como en Europa y en América Latina, respectivamente), cuando la población redundante no estaba asentada en el campo sino en las afueras de las grandes ciudades, cuando los urbanitas (muchos de ellos exrurales) encontraban molesta la presión poblacional de "los recién llegados", entonces sí se levantan las voces (y se multiplican los escritos) en referencia al problema de la emigración rural.

El poblador rural debe contar con los medios adecuados para mantener una vida digna en el lugar en que nació, parece ser el núcleo del nuevo discurso. Si se mejoraran las condiciones de vida esa población no se vería obligada a emigrar, con lo cual (y esto no estaba tan verbalizado en el discurso) la miseria urbana descendería notablemente. $\mathrm{El}$ paso siguiente fue el accionar: del discurso se pasa a los planes de desarrollo rural, de fomento agrario, de desarrollo local, etc. En muchos lugares esos planes no pasaron de meros esfuerzos voluntaristas o de rebuscadas formulaciones teóricas; en otras partes, aquellos planes sí se plasmaron en acciones concretas y con gran impacto en la población y el espacio rural (el auge del desarrollo endógeno europeo en los '80 es un claro ejemplo de ello).

Paralelamente a estos procesos, el desenvolvimiento de la vida urbana generó en una gran parte de sus habitantes una sensación de agobio, de asfixia, de desnaturalización del medio y de la vida en sí misma. Los urbanitas de ge-

cursos hicieron mella en el proceso en sí, ni en su percepción social. 
El espacio rural entre la producción y el consumo

neraciones de urbanitas empezaron a sentirse encerrados en su "espacio natural"; simultáneamente, los urbanitas de generaciones de rurales mantenían fresca la memoria colectiva de su "espacio natural". El deseo de unos y la añoranza de otros no tardó en confluir en un movimiento ideológico-cultural de revalorización de lo rural. Los primeros, buscando una Arcadia mítica; los segundos, procurando rescatar su Arcadia perdida.

En poco tiempo la sociedad en su conjunto hizo suyos aquellos planes y esta ideología cultural. El campo comenzó a ser re-visitado conceptualmente, se lo revalorizó; se lo presentó como un repositorio de valores que la sociedad industrial olvidó o destruyó. Lo natural, lo auténtico, lo puro o lo personal serían algunos de los factores que sólo podrían hallarse en el medio rural.

Lo interesante de esta revalorización reside en que parece que solamente prendió entre los urbanitas: distintas encuestas señalan que más del 65\% (en promedio) de la población de grandes ciudades europeas y del Canadá aspiraría a vivir en pequeños poblados rurales, mientras que en ambos espacios territoriales, arriba del $90 \%$ de la población rural busca salir del campo para instalarse en grandes y medianas ciudades. $^{4}$

Entonces, la reivindicación de lo rural se parece mucho a una construcción ideológica de éste por los habitantes urbanos; y como el medio rural sigue su curso, pero moldeado por el ritmo social, económico, político y cultural marcado por el espacio hegemónico (el urbano), nos hallamos ante una construcción

${ }^{4}$ Cfr. P. Ruiz Avilés (1995) y B. Jean (1995). social de la ruralidad realizada por la ciudad.

Con esto no le estamos quitando "personalidad" al medio rural. Sólo queremos significar que el "ritmo" del desenvolvimiento de este espacio está marcado por el "paso" que sigue el desarrollo urbano. A su vez, como el poder de penetración de los medios comunicacionales (de cuño urbano) es cada vez mayor, y con él también lo es su incidencia social, los valores urbanos se difunden acabadamente por el espacio rural, generando una confluencia valorativa en la cual predominan fuertemente aquellos valores.

De este modo, entonces, asistimos a dos procesos superpuestos e interrelacionados: la implementación de planes de desarrollo rural y el rescate de valores "tradicionales" del medio rural. Ambos procesos tienen en común su origen, el espacio urbano; el primero, por una cuestión físico-socioeconómica, el segundo, basado en motivos psicosociales.

¿Cuáles son los resultados de dichos procesos? En primer lugar, y como derivado de las propuestas de desarrollo rural, en la Unión Europea se destina al campo cierta cantidad de fondos para implementar distintas estrategias. La más apuntalada es, desde los años '80, la basada en la detección, impulso y apoyo a los potenciales endógenos del desarrollo local rural. Tanto a nivel nacional como de la Unión, los planes son muy numerosos y variados, pero todos coincidentes en un punto: se persigue el desarrollo del sistema rural en su conjunto: ambiente, sociedad y economía, y no sólo de uno de esos componentes. Esos planes hacen hincapié tanto en el progreso tecnoproductivo (puesto que no es posible desconocer el peso relativo que aún mantiene la actividad agropecuaria 
Marcelo Posada

sobre el sistema rural) como en el apuntalamiento de otras actividades (la pluriactividad ya mencionada), tal el caso de la descentralización industrial, de los emprendimientos artesanales, de los servicios para el consumo de ocio, etc. En otras palabras, se busca evitar los desequilibrios típicos de la etapa productivista de la Unión (cuando, por ejemplo, la necesidad de obtener alimentos se superponía - y obstaculizaba - a la necesidad de realizar un manejo sustentable de los recursos naturales). En otros ámbitos, como en Argentina, no se siguieron políticas de desarrollo rural basadas en las potencialidades endógenas del sistema, sino que se eligió implementar planes de rasgos netamente asistenciales (como el Programa Social Agropecuario) o se confundió el progreso productivo con el desarrollo rural (como ocurre con el programa Cambio Rural, que en la práctica es un plan de reconversión productiva sin apuntar a un desarrollo del medio rural en su conjunto, más allá de su denominación).

En segundo término, como consecuencia del rescate de los valores rurales (o supuestamente rurales) por parte de los urbanitas, éstos comienzan a revisitar - literalmente- al medio rural. Si se quiere, el campo pasa a ser un objeto de consumo por parte de la ciudad (primero, como consumo ideológicocultural, después, como consumo espacio-ocio). Los habitantes urbanos comienzan a trasladarse hacia el campo, tanto temporal como permanentemente. El fenómeno de la segunda residencia, la vivienda permanente en el espacio periurbano propiedad de exurbanitas, el disfrute vacacional en el espacio rural, las salidas de observación de la naturaleza (avistajes de aves, safaris fotográficos), las excursiones de corta duración de índole cultural-rural o histórico-rural, la práctica sistemática de deportes (nuevos unos, tradicionales otros) que requieren de territorios naturales, la organización de degustaciones culinarias en lugares tradicionales del medio rural, y un largo etcétera son expresiones de aquel consumo de lo rural.

Como se observa, muchas son actividades preexistentes a la actual revalorización de lo rural, otras sí son verdaderamente novedosas; todas tienen en común que el número de practicantes va en aumento. Este no es explosivo, no se trata de un boom aunque lo parezca, sino que los "usuarios" de lo rural son cada vez más numerosos, creciendo en forma moderada pero sostenida a lo largo de las dos últimas décadas.

Dada la magnitud de este fenómeno y ante sus múltiples aristas, quizá quepa la posibilidad de (o se deba) realizar un abordaje parcial del mismo. Por la magnitud que va tomando, el ejercicio del turismo en el espacio rural parece ser una elección adecuada, tanto porque se lo detecta en muy distintos espacios nacionales (desde la Unión Europea hasta Chile, desde Canadá hasta Argentina) como porque el número de actores involucrados y de recursos movilizados es importante (si bien se carecen de datos cuantitativos confiables para definir con exactitud dicha importancia).

\section{EL CASO DEL TURISMO EN EL ESPACIO RURAL: ALGUNAS PRECISIONES}

Un cambio de ambiente, un tipo de vida diferente que les permita recuperar fuerzas.

Un acercamiento a la naturaleza y a las formas de vida tradicionales.

Un contacto con la gente local en un intento de compensar la despersonalización de las ciudades. 
El espacio rural entre la producción y el consumo

Un lugar tranquilo, sin ruidos y no masificado.

En definitiva, algo auténtico $y$ natural. ${ }^{5}$

Estos serían los objetivos que buscan los consumidores de ocio en el espacio rural según un documento de la administración turística española. Como se puede observar, los reclamos de los usuarios coinciden claramente con varios de los rasgos que impulsan al consumo del medio rural como espacio-ocio, que ya mencionamos más arriba.

En qué consiste este tipo de consumo. Al final de la sección anterior mencionamos que la práctica turística en el espacio rural es el más difundido de tal estilo de consumo. Genéricamente por turismo entendemos al conjunto de actividades económicas (es decir rentadas), constituidas por bienes y servicios, que efectúa un colectivo poblacional estable ofertándolo a otro colectivo poblacional temporal. Una acepción muy amplia nos permitiría considerar que cualquier emprendimiento con estas características que se realice fuera del medio urbano puede ser considerado turismo rural.

Sin embargo, parece más adecuado conceptualizar a tal tipo de consumo de ocio como "turismo en el espacio rural", ${ }^{6}$ reservando la expresión "turismo rural" para un tipo especial de aquél, según veremos luego.

Muchas son las expresiones que se utilizan como sinónimos para designar

5 Dirección General de Política Turística (1994:14).

${ }^{6} \mathrm{~J}$. Cals et al. (1995: 23) sostienen que éste debe conceptualizarse de forma tal que “(..) comprenda todo tipo de actividades turísticas que incidan, directa o indirectamente, sobre las condiciones de vida de los habitantes del medio rural y sobre sus perspectivas de progreso." distintas actividades ejercidas en el medio rural: agroturismo, turismo rural, turismo verde, turismo aventura, turismo alternativo, turismo ecológico, ecoturismo, turismo natural, turismo cinegético, turismo de avistaje, etc. No obstante, no siempre significan lo mismo; varios de estos términos se referencian en muy diferentes actividades, a veces excluyentes entre sí. Veamos algunos de estos conceptos.

Una primera diferenciación de términos puede realizarse en base a un criterio no observable a simple vista, pero de profundo impacto en el medio: en dónde se acumulan las rentas generadas por las actividades que nos ocupan. Así, tendríamos tres espacios de acumulación que se corresponden con otros tantos núcleos dinamizadores del consumo de ocio. Si el núcleo es la misma unidad de producción agropecuaria, la cual organiza y ejecuta las actividades de consumo de ocio, estaríamos ante lo que podemos denominar netamente agroturismo, puesto que la inversión es genuinamente realizada por la unidad y en ella quedan las rentas que se obtengan. Si el núcleo organizador y ejecutor reside en el medio rural -digamos en la comunidad-y no necesariamente en la unidad agropecuaria, las rentas podrán acumularse en el ámbito rural (y distribuirse acorde a su estructura societal); en este caso nos encontramos ante lo que conocemos como turismo rural. Ahora, si la organización y ejecución escapa al ámbito rural (de la unidad y la comunidad), consistiendo aquél sólo en el soporte físico de las actividades (más allá de lo discursivo que las fundamenta) y por ende las rentas se acumulan en el ámbito urbano, estaríamos ante un tipo de turismo en el espacio rural. ${ }^{7}$

\footnotetext{
7 Algunas líneas en torno a este análisis pueden encontrarse en el artículo de J. Calatrava y P. Ruiz (1993).
} 
Marcelo Posada

Otro camino para enfocar las diferencias entre términos de usos equívocos consiste en analizar al conjunto de actividades de referencia en base a su oferta de bienes y servicios y a los valores a los que responde su ejercicio. Esta vez se trata de una diferenciación más claramente observable; veamos:

a) agroturismo: consiste en aquellas actividades turísticas que se desarrollan integramente dentro de una explotación agropecuaria, desde el hospedaje hasta la comida y las recreaciones. ${ }^{8}$

b) turismo verde: es aquel turismo que se ejerce en el medio no urbano, tanto en espacios correspondientes a unidades agropecuarias como en espacios naturales (protegidos - un parque o una reserva natural - o no resguardados especialmente). En su base radican los valores más amplios de rescate del mundo rural: contacto con el ambiente natural y cultural rural, el rescate del patrimonio arquitectónico e histórico de ese ambiente, la contemplación de la naturaleza y el paisaje, el goce del silencio natural, etc.

c) turismo alternativo: en este caso estamos ante un cúmulo de actividades que se definen por lo que no son: no son aquellas que se desempeñan en los lugares tradicionales de vacaciones, es decir, son esencialmente diferentes a las del turismo de masas. En general tienden a idearse, organizarse y ejecutarse en oposición a las de este último tipo de turismo: atención personalizada vs. aten-

\footnotetext{
${ }^{8}$ En base a esta conceptualización creemos que ésta es la expresión que mejor se ajusta a lo que se conoce genéricamente en Argentina como "turismo de estancia": el alojamiento, las comidas y las actividades recreativas se llevan a cabo en el mismo establecimiento, en este caso, en los cascos de las viejas estancias de principios de siglo.
}

ción estandarizada; alojamientos seleccionados vs. habitaciones o viviendas de grandes conglomerados vacacionales; mayor contacto con el medio natural vs. artificialización de la naturaleza; etc.

d) turismo ecológico: consiste en aquellas actividades motivadas fundamentalmente por valores asentados en el rescate de la naturaleza, pero sin radicalizaciones. Esto es, se implementan actividades procurando el menor impacto sobre el medio, pero se mantiene la consideración acerca de que ese medio es el soporte de las actividades y no algo que, de tan frágil, no deba ser usufructuado de ninguna manera.

e) ecoturismo: es aquel conjunto de actividades turísticas que se llevan a cabo guiadas por el disfrute más agudo de los valores recién mencionados, apuntando a una complementación cuasiperfecta con el sustrato natural, procurando por todos los medios eludir los problemas de la masificación (aun aquella proveniente del turismo ecológico).

Con esto no termina el listado, puesto que podríamos continuar con aquellas actividades que se desarrollan sobre el espacio rural y provienen de un tronco en común, el deportivo. No se trata de acciones nuevas, sino que el aumento del número de practicantes permite considerar un tipo extra de desarrollo turístico, el turismo de deportes: el turismo cinegético, el derivado del ejercicio de la pesca deportiva, el del alpinismo, el ecuestre, etc. Un subtipo interesante (por la magnitud que va adquiriendo) es el turismo de deportes de aventura (mountain bike, rafting, canotaje, escalada, hidrospeed, etc.).

De la amplia gama de conceptualizaciones reseñadas más arriba, el agroturismo y el turismo rural (según la primera gama de interpretaciones que ya 
El espacio rural entre la producción y el consumo

indicamos) son aquellos emprendimientos que mayor impacto cuanti y cualitativo ejercen sobre el medio rural (tanto el sustrato ambiental como en lo referente a lo socioeconómico y cultural).

Dos son los elementos constitutivos del turismo rural que concitan la atención de los analistas. Por un lado, su pertenencia al espectro de la pluriactividad rural; por otro lado, las mutaciones que origina en la conformación del espacio rural.

La necesidad de complementación de rentas por parte de los productores agropecuarios es, más allá de coyunturas de precios desfavorables, una realidad creciente. Cuanto menor es la dimensión económica de la explotación, mayor será esa necesidad. La estrategia más difundida para hacer frente a esa situación es la dedicación part-time a la producción agraria (el ATP ya mencionado). Así, vemos que el $28 \%$ de los productores de la región pampeana desempeñan una actividad extrapredial, porcentaje que se eleva hasta alcanzar a más de un tercio del total de productores si consideramos a todo el país. ${ }^{9}$

Dentro de este esquema, el turismo rural constituye una de las actividades generadoras de rentas complementarias articuladas a esas estrategias de ATP. Con una importante corriente de análisis en Europa, este tipo de emprendimiento es de más o menos reciente implementación en nuestro país. ${ }^{10}$

El estudio de los procesos desarrollados en Europa y las primeras indagaciones en torno a la situación imperante en nuestro medio, acompañado del aná-

\footnotetext{
9 Cfr. M. Posada et al. (1996).

10 Los estudios europeos sobre el tema constituyen un voluminoso cuerpo. Se desta-
}

lisis de los cambios conceptuales y valorativos que hemos descrito en la otra sección, nos permiten señalar algunos de los factores que favorecen la expansión de este tipo de turismo (y, por ende, generan el escenario adecuado para su transformación en rentas rurales complementarias). Estos son:

a) una tendencia a la saturación y congestión de las zonas turísticas tradicionales.

b) la creciente demanda por el usufructo de espacios abiertos para la práctica de diversas actividades lúdicas, deportivas y de distracción intelectual y/o ambiental no puede ser satisfecha por los espacios turísticos/vacacionales tradicionales.

c) una propensión social a manifestar interés por el patrimonio natural y cultural rural y a "disfrutar" del mismo.

d) el nuevo estilo de vacaciones imperante en las sociedades más desarrolladas (lapsos cortos y fuera de temporada, aprovechamiento de fines de semana extensos, facilidad de acceso con medios de locomoción propios, diferenciación y particularismo en la atención, etc.) no encuentra un espacio adecuado en el sistema turístico tradicional.

can entre otros: J. Calatrava Requena (1984 y 1992); J. Calatrava Requena y R. Ruiz Avilés (1993); Conseil de l'Europe (1988); P. Ruiz Avilés (1995); M. Bonneau (1984); C.C.E. (1992); V. Bote Gómez (1981); D. García Ramon et al. (1995); H. Kariel y P. Kariel (1982); M. Bunce (1982).

Entre las referencias bibliográficas para el caso argentino podemos mencionar a: E. Barrera (1995 y 1996); H. Vecchiet (1991); R. Sobral y M. Prieto (1996); INTA (1994 y 1996); F. Arella (1996). 
Marcelo Posada

El agroturismo y el turismo rural pueden responder favorablemente a estas nuevas demandas sociales. Sin embargo, no todo espacio rural es factible de transformarse en un espacio turístico rural. Desde factores sociales hasta de infraestructura, pasando por el tipo de externalidades que genere, son múltiples los elementos a considerar en el análisis de este tipo de emprendimientos. Sin realizar un análisis pormenorizado, enunciemos algunos de ellos: $a$ ) debe ser una actividad natural, que se desarrolle en pleno contacto con el medio ambiente natural; $b$ ) será una actividad limitada, en el sentido de que no podrá concentrar la totalidad de la oferta económica del área, sino que constituirá una complementación a las rentas originadas en las actividades agrarias tradicionales; c) debe localizarse sobre núcleos poblacionales preexistentes, no generando nuevos asentamientos ad hoc; d) deberá contribuir a la generación de empleos locales, por medio de la oferta indirecta de otros bienes y servicios; e) será activo y recreativo, desde la perspectiva del turista; $f$ ) fomentará la instalación de infraestructuras de comunicaciones y servicios de uso permanente, y no sólo de usufructo para el flujo turístico estacional; $g$ ) debe contribuir a estrechar el intercambio entre el campo y la ciudad, pero manteniendo cada ámbito su individualidad (o lo que queda de ella); $h$ ) cooperará en la articulación de políticas de ordenamiento territorial con base local.

Los estudios revisados y las entrevistas que hemos efectuado indican que el tipo de consumidores de esta variedad de turismo se ubica en el espectro de renta media-alta, que vacaciona en familia y que posee estudio de grado superior. En general se trata de turistas que residen en grandes núcleos urbanos, aunque no necesariamente habitan edificios de multipropiedad. Una en- cuesta española señala que las principales motivaciones para recurrir a este tipo de turismo son: la búsqueda de tranquilidad y reposo, el paisaje rural, el alcanzar un contacto personalizado con la población local, la posibilidad de realizar una amplia gama de actividades lúdicas, el acercamiento a los valores de la cultura local, etc. ${ }^{11}$ Los operadores de agroturismo y turismo rural entrevistados señalan motivaciones muy similares para el caso de nuestro país.

De esta manera, el turismo rural se expresa como función de dos componentes: el confort y el ambiente. El primero expresado por la existencia de las condiciones habitacionales y de profesionalidad mínimas que exige el mencionado target, pero sin incurrir en la "industrialización" de esta modalidad de turismo. El segundo implica la existencia de recursos turísticos intrínsecos, sobre los cuales se deben crear un conjunto de condiciones que los hagan atractivos, basadas - fundamentalmente- en la diferenciación.

El desarrollo de este tipo de turismo conlleva la reasignación de espacios: de áreas productivas desde lo agropecuario, hacia áreas productivas pero desde lo turístico: cotos de caza y/o de pesca, circuitos de mountain-bike o de cabalgatas, camping, parcelas para la labranza por parte de los turistas, etc. Aun en la misma vivienda de la explotación que recurra a esta estrategia de complementación de rentas ocurren reasignaciones: habitaciones que pasan a ser de los huéspedes temporarios, se comparte la mesa en los horarios de comidas, el núcleo inmediato receptor de los trabajos cotidianos del hogar se amplía (la familia más los turistas hospedados), etc. La expresión más acabada de este desa(1995). 
El espacio rural entre la producción y el consumo

rrollo son lo que en España se conoce como "casas de labranzas": tradicionales explotaciones agrarias que reciben turistas por un corto lapso, pero que no interrumpen el normal desarrollo de sus actividades agropecuarias, las cuales son realizadas de manera recreativa por esos huéspedes. De manera similar, varios de los cascos de estancias bonaerenses que reciben huéspedes realizan su cotidianeidad incorporándolos a su rutina (horarios de comida, de descanso, etc.).

En otras palabras, la organización del espacio rural adquiere otro cariz a medida que se incrementa el desarrollo del turismo rural. Cuando éste es impulsado por política públicas, como es el caso de los países de la Unión Europea, esa reorganización es mucho más profunda. $\mathrm{El}$ acicate a la salida de producción de tierras agrícolas (en el marco de la Política Agraria Comunitaria) encontró en el turismo rural un aliado: los agricultores impelidos a reducir su área de trabajo encontraron un ingreso compensatorio en este tipo de desarrollo turístico. En muchos casos, explotaciones enteras se reconvirtieron en cotos de caza o en reservorios para los practicantes de la observación de la naturaleza (especialmente para los aficionados a la ornitología). Incluso, completos planes de desarrollo rural giraron en torno a este tipo de turismo, tal el caso de la zona de las islas de Escocia.

La situación en Argentina es, obviamente, muy distinta. Sin planes oficiales de apoyo al turismo rural, con un perfil cultural del colectivo agrario notablemente diferente del europeo, y con una estructura productiva agraria también distinta, se hace dificultoso extrapolar la experiencia de la Unión Europea. Esto no significa que no existan incipientes iniciativas en torno a este tipo de actividades.
Muchos productores, por sí o por estímulo de otros actores extraagrarios, recurrieron a implementar estrategias de diversificación de ingresos a través del turismo rural. Notablemente, es en la región pampeana - la más rica y dinámica del país- donde se detecta una elevada concentración de este tipo de emprendimientos. La combinación de playas relativamente poco explotadas, sierras, valles interserranos, montes naturales y campos llanos brinda un panorama natural alentador.

Desde el poblamiento serrano con caprinos salvajes y de montes naturales con cerdos - montaraces - hasta el cultivo de pejerreyes en lagunas privadas, pasando por la instalación de un gran complejo internacional destinado al agroturismo (con inversiones de capital italiano), son varios los emprendimientos e importantes los efectos locales que acarrean. El incremento del flujo de turistas, la creación de nuevos empleos, la construcción de cierta infraestructura de uso permanente, la mayor demanda de bienes y servicios locales, etc., son algunos de esos efectos.

Obviamente que esas iniciativas privadas, aisladas y desarticuladas no pasarán más que de eso si no cuentan con el respaldo de políticas amplias, que las contengan e insuflen mayor dinamismo. El aparato estatal no debe mantenerse al margen de estos emprendimientos. La experiencia europea a este respecto es enriquecedora: desde la administración central y hasta los gobiernos locales se colabora con tales iniciativas; sin esa contención pública difícilmente el agroturismo y el turismo rural hubieran podido desarrollarse como lo están hoy en la Unión Europea.

Argentina no es la excepción a esa necesidad de apoyo estatal. La acción de la administración debería basarse en tres 
Marcelo Posada

ejes: a) el mejoramiento de las prestaciones turísticas mediante ayudas destinadas a la organización de estos emprendimientos; $b$ ) el estímulo a una oferta turística más elaborada (no sólo del tipo bed \& breakfast); c) la integración del emprendimiento turístico con la actividad agraria principal de la explotación. En buena medida, estos ejes se articulan con uno de los vértices que surge del análisis de las implicancias del turismo rural respecto al medio en el que se inserta. En efecto, este tipo de emprendimiento procura aprovechar (y de hecho lo hace) el potencial de desarrollo endógeno del territorio sobre el que se asienta. Este potencial se nutre de la riqueza paisajística o natural, de la ubicación estratégica del espacio, del patrimonio cultural, inmobiliario o monumental existente en el área, y de la capacidad empresarial y adaptativa de la población involucrada. Cuando estos factores se interconectan y el potencial se dinamiza, el emprendimiento turístico está en condiciones de transformarse en el núcleo de un proceso de desarrollo local. Si esto no ocurre, si la desarticulación es la regla (como en la casi totalidad de los casos detectados en nuestro país), entonces estamos frente a un emprendimiento empresarial, individual, sin contacto con el medio (más allá de lo imprescindible) y cuyas rentas generadas, seguramente, no quedarán en el área rural.

\section{A MODO DE CONCLUSIÓN}

El turismo rural es un tipo de emprendimiento muy adecuado para implementar estrategias de desarrollo local. En particular, las casi nulas barreras de entrada a la actividad constituyen un acicate para que distintos emprendimientos se lleven a cabo. Claro está, esta facilidad de entrada no es equivalente a facilidad de mantenimiento, puesto que la perduración de esos emprendimientos requerirá del desarrollo de una serie de habilidades organizativas y de dirección que implican un cierto nivel de adecuación educativa y un compromiso estable con la actividad.

Esas bajas barreras de entrada permiten la implementación de lo que un autor denominó "estrategias artesanales". ${ }^{12}$ Esto es, la creación de una oferta no concentrada, de pequeña escala y altamente diversificada de bienes y servicios turísticos, lo cual está al alcance de los actores sociales de un territorio dado, aun con severas restricciones financieras. Lo fundamental, además del compromiso y la capacitación paulatina ya mencionada, reside en el impulso que pueda brindar el aparato estatal. Resulta paradójico: el desarrollo endógeno requiere de un impulso exógeno. Sin embargo, así funcionó en la Unión Europea y así parecería que deberá suceder en nuestro país. Los obstáculos para este tipo de emprendimientos son numerosos, desde la desarticulación existente en la operatoria turística hasta la carencia de experiencia en administración hotelera, desde la atomización de la oferta hasta los peligros derivados de la sobreexplotación turística de los recursos y valores que le son inherentes a su desarrollo (el paisaje natural y la tranquilidad del campo, por citar sólo dos de los más básicos pero simultáneamente más frágiles).

Un adecuado diagnóstico de la situación real y potencial del turismo rural y del agroturismo permitiría señalar los puntos débiles y las fortalezas de este tipo de emprendimiento. Y aún más, posibilitaría la detección de las oportunidades de transformarlos en núcleos de procesos de desarrollo endógeno que logren suplir (aunque sea en forma par-

12 V. Bote Gómez (1988). 
El espacio rural entre la producción y el consumo

cial) las falencias de las políticas de amplio espectro.

La revalorización de lo rural por parte de los habitantes urbanos y la necesidad de implementar nuevas alternativas productivas no agropecuarias confluyen en delinear un escenario que impactará (y ya lo está haciendo) muy fuertemente en el patrón organizativo del espacio rural. El conocimiento del porqué, cómo y dónde se producen esos cambios será de vital importancia para operar sobre los procesos, ya sea acompañándolos, brindándoles algún tipo de asistencia, o redireccionándolos en pos de un desarrollo más armónico con el medio físico y social del ámbito rural.

\section{BiBLIOGRAFÍA}

Arella, Felipe (1996). "Agroturismo como alternativa productiva”, en Super Campo, $\mathrm{n}^{\circ} 26$, Buenos Aires, noviembre, p. 88-94.

Barrera, Ernesto (1995). "Un agronegocio que surge. El turismo rural”, en Presencia, $\mathrm{n}^{\circ}$ 37, Bariloche, INTA-EEA Bariloche, p. 38-43.

Barrera, Ernesto (1996). "Red Argentina de Turismo Rural: RATUR. Fundamentos para su organización. Propuesta de trabajo", en II Seminario Internacional Agroturismo, Buenos Aires, INTAIESR, p. 3-20.

Bonneau, Marcel (1984). "Le tourisme rural en France et ses conséquences pour l'espace rural", en A.A.V.V. Coloquio hispano-francés sobre espacios rurales, Madrid (España, MAPA, tomo II, p. 33-42.

Bote Gómez, Venancio (1981). "La estrategia del turismo rural integrado en España”, en A.A.V.V. Supervivencia en la montaña, Madrid (España), MAPA.

Bote Gómez, Venancio (1988). Turismo en espacio rural. Rehabilitación del patrimonio sociocultural y de la economía lo- cal, Madrid (España), Editorial Popular.

Bote Gómez, Venancio (1993). "El turismo y la rehabilitación y conservación del patrimonio rural en España”, en Estudios y perspectivas en turismo, vol. $2, \mathrm{n}^{\circ} 1$, Buenos Aires, enero, p. 6577.

Bunce, M. (1982). Rural settlement in an urban world, London (UK), Croom Helm.

Calatrava Requena, Javier y P. Ruiz Avilés (1993). "El turismo, una oportunidad para las zonas rurales desfavorecidas?", en LEADER Magazine, $\mathrm{n}^{\circ} 4$, otoño, p. 6-9.

Calatrava Requena, Javier (1984). "Análisis de la potencialidad del turismo rural como elemento generador de rentas complementarias en zonas en depresión socioeconómica: el caso de las Alpujarras granadinas", en A.A.V.V. Coloquio hispano-francés sobre espacios rurales, Madrid (España), MAPA, tomo II, p. 305-328.

Calatrava Requena, Javier (1992). "El turismo rural como recurso endógeno en el desarrollo local", en C. del Canto Fresno (coord.). Desarrollo rural. Ejemplos europeos, Madrid (España), MAPA, p. 67-91.

Cals, Joan et al. (1995). El turismo en el desarrollo rural de España, Madrid (España), MAPA.

C.C.E. (1992). El futuro del mundo rural, Madrid (España), MAPA.

Conseil de l'Europe (1988). Le tourisme rural en Europe, E.E.C.

Dirección General de Política Turística (1994). Manual del empresario de turismo rural, Madrid (España).

García Ramón, María et al. (1995). "Farm tourism, gender and the environment in Spain", in Annals of Tourism Research, vol. 22, n ${ }^{\circ} 2$, p. 267-282.

INTA (1994). Conclusiones del I Seminario Internacional Agroturismo, Bariloche. 
Marcelo Posada

INTA (1996). II Seminario Internacional de Agroturismo. Sintesis organizativa y conclusiones, Buenos Aires.

Jean, Bruno (1995). "Decadencia o renacimiento: la agricultura y la ruralidad en Canadá en el cruce de caminos”, en Intersecciones, $\mathrm{n}^{\circ} 1$, Olavarría, diciembre, p. 85-96.

Kariel, H. and P. Kariel (1982). "Sociocultural impacts of tourism: an example from the Austrian Alps", in Geografiska Annaler, vol. 64 B, p. 1-16.

Nogué i Font, Joan (1988). "El fenómeno neorrural", en Agricultura y Sociedad, $\mathrm{n}^{\circ}$ 47, Madrid (España), abriljunio, p. 145-175.

Posada, Marcelo et al. (1996). "O emprego agrícola na Argentina: processos recentes e tendências evolutivas", na Cadernos do CEAS, $\mathrm{n}^{\circ}$ 164, Salvador (Brasil), julho-agosto, p. 20-36.
Ruiz Avilés, Pedro (1995). "Perspectivas y nuevas orientaciones del turismo rural", en E. Ramos Real y J. Cruz Villalón (coord.). Hacia un nuevo sistema rural, Madrid (España), MAPA, p. 495-515.

Sienrra, Celestino (1946). Campo y ciudad. El problema agrario argentino, Buenos Aires, La Vanguardia.

Sobral, R. y M. Prieto (1996). "Evaluación de la aptitud turística de establecimientos agropecuarios: una aplicación para la actividad observación de aves (birdwatching)", en II Seminario Internacional Agroturismo, Buenos Aires, INTA-IESR, p. 21-30.

Vecchiet, Hugo (1991). "Hotelería-resort de estancias", en Revista Latinoamericana de Turismo, vol. $1, \mathrm{n}^{\circ} 4$, Buenos Aires, octubre, p. 267-272.

\section{Pontificia Universidad Católica de Chile Instituto de Estudios Urbanos Programa de Postgrado Marzo 2000 - Julio 2001}

MAGISTER EN ASENTAMIENTOS HUMANOS Y MEDIO AMBIENTE Tres semestres académicos incluido período de tesis.

\section{Admisión}

Orientado a licenciados en Administración, Agronomía, Arquitectura, Derecho, Economía, Geografía, Ingeniería, Ciencias de la Salud, Sociología y/o similares.

\section{Becas y beneficios}

Alumnos nacionales tienen opción a préstamos y/o becas de la Universidad. Los alumnos extranjeros pueden optar a Becas OEA, BID, MUTIS.

Becas AGCI para centroamericanos, etc., y/o acogerse a Convenios Intergubernamentales.

\section{Postulaciones}

dirigirse a: Jefe de Programa de Magister en Asentamientos Humanos y Medio Ambiente.

INSTITUTO DE ESTUDIOS URBANOS

Fonos: 6865510/2325057 - Anexo 5510. Fax: 56-2-2328805

E-mail: ptorrena@puc.cl. Casilla 16002-Correo 9. Santiago-Chile 
El espacio rural entre la producción y el consumo 